\title{
Oceanography
}

CITATION

Katsaros, K.B. 2005. Review of An Introduction to Ocean Remote Sensing, by S. Martin.

Oceanography 18(3):86-89, http://dx.doi.org/10.5670/oceanog.2005.36.

DOI

http://dx.doi.org/10.5670/oceanog.2005.36

COPYRIGHT

This article has been published in Oceanography, Volume 18, Number 3, a quarterly journal of The Oceanography Society. Copyright 2005 by The Oceanography Society. All rights reserved.

USAGE

Permission is granted to copy this article for use in teaching and research. Republication, systematic reproduction, or collective redistribution of any portion of this article by photocopy machine, reposting, or other means is permitted only with the approval of The Oceanography Society. Send all correspondence to: info@tos.org or The Oceanography Society, PO Box 1931, Rockville, MD 20849-1931, USA. 
mentals like the equilibrium line or ablation area; at the same time, many really critical concepts are absent_-in this case, for example, those of summer and winter balance, balance gradients, accumulation area ratio, or balance amplitude.

More troubling to me, though, than the addition of what could be confusing detail, is the absence of fundamentals. Some fundamentals are covered, to be sure: there are excellent descriptions of glacier morphology, good chapters on the structural features of glaciers, on the geological record of glaciation, and on the role of glaciers in global hydrology. But missing is any real discussion of important topics at the level of the dynamic nature of the Antarctic ice streams, the insights gained into ice sheet/climate interaction from the GISP II/GRIP projects, and the significance of Heinrich events. An entire chapter devoted to glacial debris gives a complete nomenclature but no discussion whatever of glaciers in a global context as erosive agents or their role in global sediment transport-no indication as to why we would need such a nomenclature.

Missing altogether is any mention of numerical modeling, of the motivations for making measurements, of our knowledge of the physical properties of water in its various phases, or of the existence of a constitutive law for ice. There is no

\section{An Introduction to Ocean Remote Sensing}

By Seelye Martin, Cambridge

University Press, 2004, 454 pages

Hardcover: ISBN 0521802806, \$75 US

\section{REVIEWED BY KRISTINA B. KATSAROS}

\section{An Introduction to Ocean Remote Sens-}

ing by Seelye Martin is an excellent textbook for teaching remote sensing of the oceans at the beginning of the $21^{\text {st }}$ century. Since 1987, Dr. Martin has taught remote sensing to graduate students and senior undergraduates. Ocean Remote Sensing is a classical textbook that starts with fundamentals and basic principles. It then covers the entire field, which has been difficult to do in the past because some aspects of remote sensing were better developed than others. Now, with 40 years of meteorology and oceanography from space behind us, (beginning with the Nimbus I satellite and the early infrared measurements of sea-surface temperature in the mid-1960s), the time was ripe for a fundamental textbook on remote sensing of the ocean. There are numerous satellite systems currently gathering oceanographic data routinely, and many more are planned. The basics of the techniques are now well understood, so that more oceanographers can rely on remotely sensed data. We have now used a broad range of the electromagnetic spectrum, from the visible and infrared mention of the existence of a mathematical framework for thinking quantitatively about glaciers, or even a suggestion that one might want to have such a framework. The qualitative view of glaciers is both inspiring and of good scientific utility, but to allow it to eclipse the quantitative view of glaciers in this way will not serve well the needs of any new student of Earth sciences, regardless of their motivations for coming into the subject or their ultimate scientific destination. 四

W.T. Pfeffer (pfeffer@tintin.colorado.edu) is Associate Professor, Institute of Arctic and Alpine Research, University of Colorado, Boulder, CO, USA.

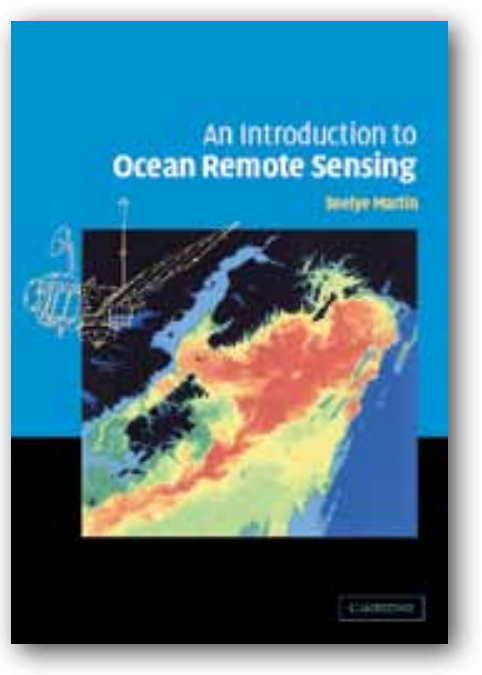

wavelengths, to many frequencies in the microwave region. Remote-sensing techniques have been used in passive and active modes. The active mode has mostly been used from space in the microwave range, but lasers using visible light are being used from aircraft and are planned for satellite missions. Every graduating oceanography student should now be 
well versed in this important data source.

Although the textbook is about ocean remote sensing, I mentioned meteorology because satellite oceanography depends on developments in satellite meteorology, as the ocean is observed from space through the intervening atmosphere. When using visible and infrared wavelengths to view the ocean, images must be "cloud cleared" (cloudy regions in the field of view are identified and such pixels, individual observations, removed). Similarly, signals from the ocean must be corrected for atmospheric transmission and scattering. Dr. Martin points out that 90 percent of the signal that reaches a satellite in these wavelength bands comes from the atmosphere. This signal must be accurately taken into account so that the remaining 10 percent emanating from the ocean will be correctly interpreted.

Dr. Martin should be commended for the systematic and thorough structure of his book. The first section provides the motivation for remote sensing and study of the oceans for societal interests. Commercial, naval operations, fisheries, and recreation are mentioned, as well as the oceans' role in generation of extreme weather and climate variability. He points out that 50 percent of the global population lives within $50 \mathrm{~km}$ of coastlines, which are vulnerable to natural hazards such as sea-level rise, tsunamis, and tropical cyclones, but also to the coastal effects of urban run-off, and waste and sewage disposal.

Chapter 1 covers the basics of typical satellite orbits and the associated sampling obtained by satellites. This chapter also covers imaging techniques and provides an overview of satellite systems since 1978 through 2007, which is very helpful for readers of this vast subject. Dr. Martin provides a list of symbols and their definition prior to this chapter, which is a useful feature especially for newcomers to the field.

The next four chapters cover ocean surface phenomena, electromagnetic radiation, atmospheric properties, and radiative transfer. Chapter 2 discusses ocean surface wind and waves, currents, sea-surface height, and sea ice. Discussions of sea-surface temperature (SST) and color are reserved for later chapters. Chapter 3 deals with basic electromagnetic theory, fundamentals of visible and infrared radiation, optics, scattering theory, transmission, and absorption (in atmosphere and ocean). Dr. Martin also discusses the ideal instrument, but does not discuss detectors of radiation. He concentrates on the basic physics of the electromagnetic transmission and on how images are obtained. Chapter 4 covers basic knowledge about the atmosphere, water vapor, clouds, aerosols, and ozone. Extinction of radiation by atmospheric gases and various scattering mechanisms are derived and application of this knowledge to remote sensing of the sea is emphasized. Chapter 5 provides detail about reflection and scattering from the ocean surface and transmission through the air-water interface as well as absorption and scattering in seawater.

Chapter 6 is devoted to ocean color and the interpretation of images. Dr. Martin focuses on the empirical and semi-analytic algorithms for interpreting the images in terms of chlorophyll $a$ and discusses reflectance and fluorescence by chlorophyll. In particular, he discusses the Sea-viewing Wide Field- of-view Sensor (SeaWifs) and Moderate Resolution Imaging Spectroradiometer (MODIS) instruments. In this chapter, several sections are devoted to the atmospheric corrections and the role of atmospheric aerosol in modifying ocean color observations.

Chapter 7 examines infrared SST observations. This field is one of the most developed in oceanographic remote sensing and the data are used widely. The subject remains open for research due to the complicated air-sea interaction processes that modify the temperature gradient just below the sea surface. The author covers these details in a succinct and clear manner and discusses the two wellknown sensors, the Advanced Very High Resolution Radiometer (AVHRR), and MODIS. The now classic AVHRR is carried by NOAA satellites, whose data are used globally for numerous applications in real time. MODIS is carried on two recent NASA satellites, Aqua and Terra. Dr. Martin also includes a discussion of the European Along-Track Scanning Radiometer (ATSR). Dr. Martin spends a couple of sections on the important applications of remotely sensed SST, primarily for the El Niño/La Niña observations (especially for the year 1998) and for global SST mapping.

Chapter 8 deals with the fundamentals of microwave passive instrumentation, such as antennas and scanning patterns, and describes some of the well-known instruments such as the Special Sensor Microwave/Imager (SSM/I), which has a history of continuous presence in space since 1987 on U.S. Defense Meteorological Satellites. This chapter also describes the TRMM Microwave Imager (TMI), a new sensor, and the 


\section{BOOKS RECEIVED FOR REVIEW}

Satellite Monitoring of Inland and Coastal Water Quality: Retrospection, Introspection and Future Directions

by Robert P. Bukata (CRC Press, 272 pages)

Sounds in the Sea: From Ocean Acoustics to Acoustical Oceanography by Herman Medwin (Cambridge University Press, 670 pages)

Marine Turbulence: Theories, Observations and Models, Results of the CARTUM Project

edited by Helmut Baumert, John Simpson, and Jürgen Sündermann

(Cambridge University Press, 672 pages)

Leaving the Lectern: Cooperative Learning and the Critical First Days of Students Working in Groups

by Dean McManus (Anker Publishing, 232 pages)

Baroclinic Tides: Theoretical Modeling and Observational Evidence

by Vasiliy Vlasenko, Nataliya Stashchuk, and Kolumban Hutter

(Cambridge University Press, 351 pages)

Advanced Microwave Scanning Radiometer (AMSR). The TRMM is the Tropical Rainfall Measuring Mission, and the TMI operates in conjunction with a rain radar on this satellite. Chapter 9 discusses passive microwave observations of the atmosphere and ocean surface, and includes all the relevant issues, however, this chapter is not bogged down in the enormous amount of detail that this field has garnered over the past 30 years. Dr. Martin still includes the effects of sea foam, azimuthal variation in emission from a wind-roughened sea surface, and variations due to polarization. The chapter discusses temperature and salinity measurements by passive microwave instruments, the latter possibility currently planned only for future missions.

In Chapter 10, Dr. Martin turns to radars, starting with fundamentals of the radar equation, various signal generation processes, and Doppler binning of the retrieved backscattered signal. In Chapter 11 , he turns to the use of radar "scatterometers" for measurement of surface wind on the sea. This idea was first tested by Seasat in 1978, and has now become well established with both U.S./Japanese collaboration in launching several such instruments, and the Europeans launching two such scatterometers on the European Remote Sensing (ERS) satellites 1 and 2. The European instruments have employed a different wavelength (Cband) than the U.S.-built instruments (Ku-band), allowing knowledge to be gained about how these scatterometers interact with the sea surface wave fields. This chapter also discusses polar ice studies employing scatterometers.

Another important accomplishment of microwave radars is the development of the altimeter, a nadir-viewing radar, which measures the height of the ocean relative to a geoid. Chapter 12 starts with the fundamentals of Earth's shape and the various orbits selected for sampling by altimeters to account for tides and other temporal variations of sea height and to avoid aliasing. Again, several important instruments are discussed, notably the TOPography EXperiment (TOPEX by the United States and France) and the later JASON missions, as well as calibrations and corrections. Dr. Martin also covers the effects of surface waves on the return, from which wave height within the footprint can be determined. He discusses the effects of swell and the so-called "sea state bias" caused by the asymmetry of ocean swells' crests (narrow and peaked) and valleys (open and wide). Chapter 12 also discusses applications in terms of largescale geostrophic flow, seasonal variations in sea surface height, and Rossby wave propagation.

In Chapter 13, the author discusses imaging radars, side-looking radars (SLRs), and synthetic aperture radars (SARs). Again, he clearly and simply describes the operation and resolution of SARs. Dr. Martin includes a discussion of the amazing Canadian RADARSAT SAR and its observations of internal waves, surface slicks, and sea ice. He does not discuss the operation of this SAR in wide-swath mode, which is contributing information of structures in the surface wind (based on knowledge from scatterometers) on scales of $100 \mathrm{~m}$ and longer over areas about $400 \mathrm{x} 400$ $\mathrm{km}^{2}$. This reviewer has had the opportunity to study atmospheric convective 
clouds, rain band structures, and wind fields around hurricanes over the ocean with this instrument. It is a newer application of SAR, which is also available from the European Environmental Satellite (ENVISAT) launched in 2002. This chapter is an excellent survey of most of the uses of SAR, but cannot cover all possibilities. In general, Dr. Martin should be commended for his restraint in telling the facts and including the most important applications of each instrument without drowning the reader in detail.

Chapter 14 describes future oceanographic satellite systems from 2004 through 2019, including missions approved or proposed. It will be a very helpful reference for anyone wishing to keep up with this field in the coming 15 years. There is much more to come, so the serious oceanographer would do well to obtain this book and catch up on the field, even if he/she is not actively using remote sensing in his/her work.

Dr. Martin includes acknowledgements to all the folks who helped him in each chapter, as well as suggestions for further reading. Both of these features are valuable in terms of giving credit, and to assist the reader to go further into a subject. He ends the book in section 14.10 with Final Thoughts. Here he mentions how these technologies have given us a new view of the globe and ability to calculate important variables, such as the global uptake of carbon and its dependence on the El Niño-Southern Oscillation cycle. He suggests that, "in the next two decades, it is the task of researchers and policy makers to understand these changes and relate them to national and international societal concerns."

This book is well written and has excellent illustrations. With its judicious choice of subject matter, Ocean Remote Sensing is not only eminently practical for students and teachers of university courses, but also for practicing oceanographers and policy-makers. It fills a very different niche than the many conference books and more specialized books that present the state of the art without the fundamentals provided by Dr. Martin. 四

Kristina B. Katsaros (katsaros@whidbey. com) is Adjunct Professor, University of Miami, Miami, FL, USA, and President of the Pan Ocean Remote Sensing Conference Association.

\section{THE Oceanography WeB SITE \\ WWW.TOS.ORG/OCEANOGRAPHY}

\section{RECENT ISSUES ARE NOW AVAILABLE ONLINE!}
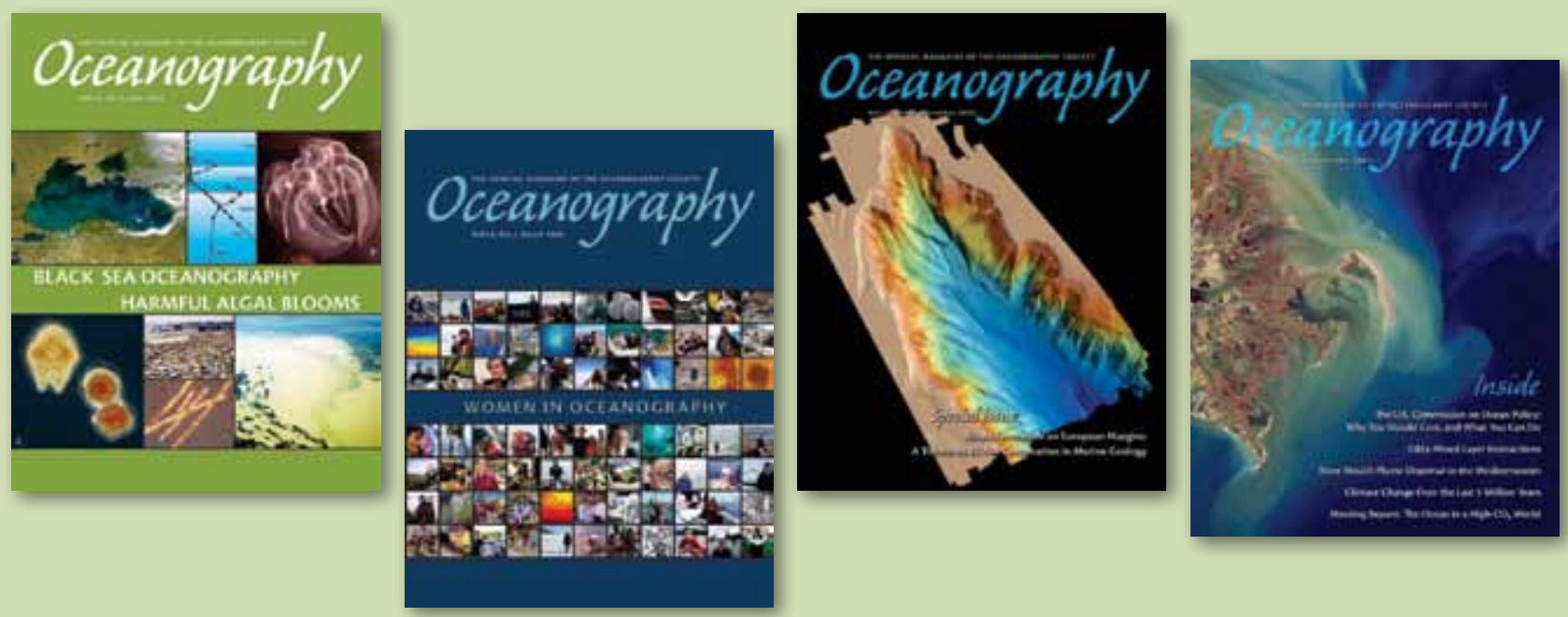